\title{
Anxiety among Adolescent Students and its Association with Socio Demographic Uariables in a Rural Block of Haryana
}

\author{
Ram Bilas Jain', Priyanka Choudhary?', Sujata Sethr, \\ Almit Kumar Xitatt, Neeraj Pawar
}

${ }^{1}$ Senior Professor, ${ }^{2}$ Post Graduate Resident, Department of Community Medicine, PGIMS, Rohtak, Haryana, India.

${ }^{3}$ Senior Professor, Department of Psychiatry, PGIMS, Rohtak, Haryana, India.

${ }^{4}$ Senior Resident, Department of Pediatrics, BPS GMCW, Khanpur Kalan, Sonepat, Haryana, India.

${ }^{5}$ Senior Resident, Department of Community and Family Medicine, AIIMS, Bhopal, Madhya Pradesh, India. DOI: https://doi.org/10.24321/2455.7048.201811

\section{Abstract}

Background: Anxiety is one of the most common psychological disorders in school-aged children and adolescents worldwide. Anxiety is associated with substantial negative effects on children's social, emotional and academic success.

Objectives: To find out the prevalence of anxiety among adolescent students and its association with sociodemographic factors in rural block Beri.

Methods: It was a cross sectional study taking the sample size of 600 (300 males and 300 females) studying in class 8th to 12th. A pre-designed, pre-tested tool SCL 90 R containing 90 items was used to screen anxiety in these students. Anxiety is one of the psychiatric morbidities screened by this tool. Cut off point of estimated raw score of 1 was used to label as anxiety.

Results: It was observed that nearly $18.5 \%$ adolescents suffered from anxiety. Anxiety was highest in 17-19 years age group (30.4\%) followed by mid adolescence phase (13-16 years). Anxiety was maximum in $10^{\text {th }}$ and $12^{\text {th }}$ standard students which were $19.3 \%$ and $24 \%$ respectively. It was significantly high among females $(23.7 \%)$ than males (13.7\%). Anxiety was maximum in upper and lower socio-economic class of students with $24.1 \%$ and $22.3 \%$ respectively. It was more among students whose mothers were unemployed (19.5\%) than those whose mothers were employed (14.6\%).

Conclusion: More than one - third (35\%) of study subjects who were apparently healthy suffered from unnoticed anxiety. Appropriate counseling through school-based screening programme is the urgent need of the hour.

Keywords: Adolescent, Anxiety, School adolescents

\section{Introduction}

Anxiety is one of the most common psychological disorders in school-aged children and adolescents worldwide. ${ }^{1}$ The prevalence rates range from $4.0 \%$ to $25.0 \%$, with an average rate of $8.0 \% .^{2,3}$ Increasing concern has been expressed

Corresponding Author: Priyanka Choudhary, Department of Community Medicine, PGIMS, Rohtak, Haryana, India.

E-mail Id: drmittalpriyanka@gmail.com

Orcid Id: https://orcid.org/0000-0001-5229-7801

How to cite this article: Jain RB, Choudhary P, Sethi S et al. Anxiety among Adolescent Students and its Association with Socio Demographic Variables in a Rural Block of Haryana. Epidem Int 2018; 3(3): 1-8. 
about the mental health of students in higher education. Concerns have been articulated by students themselves and by the academic staff who teach them. ${ }^{4}$ The World Health Report has quoted India as having a substantial prevalence of childhood and adolescent mental health disorders. ${ }^{5}$

Anxiety is one of the determinants of human behavior. It is most likely to arise from internal response or behavior that conflict with the satisfaction of other needs or motives. The concept of anxiety is utilized for explaining many psychological problems and has become a useful construct in the field of psychology.

Generally, anxiety can be either a trait anxiety or a state anxiety. A trait anxiety is a stable characteristic or trait of the person. A state anxiety is one which is aroused by some temporary condition of the environment such as examination, accident, punishment etc. Academic anxiety is a kind of state anxiety which relates to the impending danger from the environments of the academic institutions including teachers, certain subjects like Mathematics, Science, Language etc.

In India, the main documented cause of anxiety among school children and an adolescent is parents' high educational expectations and pressure for academic achievement. ${ }^{6}$ Quality of performance has become the key factor for personal progress. Parent's desire is that, their children climb the ladder of performance to as high a level as possible. This desire for high level of achievement put a lot pressure on students, teachers and school and in general, the educational system itself. In a culture that judges an individual's intellectual abilities and ascribes status on the basis of academic performance, it is perhaps not surprising that students become more anxious over their academic success and failures as they age.

Anxiety is associated with substantial negative effects on children's social, emotional and academic success. ${ }^{7}$ Specific effects include poor social and coping skills, often leading to avoidance of social interactions, loneliness, low self-esteem, perceptions of social rejection, and difficulty forming friendships. ${ }^{8,9}$ Importantly, in students, high level of anxiety could have an impact on working memory, decreased problem-solving \& reasoning abilities, school avoidance, and lower academic achievement. ${ }^{10,11}$ Anxiety is considered to be a universal phenomenon existing across cultures, although its contexts and manifestations are influenced by cultural beliefs and practices. ${ }^{12}$ Additionally, anxiety in students can affect their physical and psychological characteristics causing panic attacks, which makes them, go blank during exams, feel helpless/cold/nervous, have sweaty palms/fast breath/palpation and could even cause stomach upset.

Childhood anxiety disorders tend to be chronic and rarely remit without treatment and additional anxiety disorders may develop in adolescence and adulthood. Anxiety is highly comorbid with depression and other psychological disturbances within community and clinical populations. ${ }^{1,}$ 13, 14 A longitudinal study in New Zealand found that adolescents with anxiety disorders experienced elevated rates of anxiety, major depression, illicit-drug dependence, and educational underachievement when they entered young adulthood. ${ }^{15}$ Anxiety disorders in childhood are also predictive of other disturbances in later life including personality psychopathology, suicidality and increased substance abuse. ${ }^{15,16}$ Thus, keeping in view the harmful impact of anxiety, the present study has been planned to find out the prevalence of anxiety among school going adolescents in rural block of Haryana. Also, this study will find out the association of anxiety with socio-demographic variables like age, sex, class of students, literacy level of parents, socio-economic status and employment of mothers.

\section{Methods}

The study was conducted in a rural block of Haryana. Study duration was one year from October 2016 to September 2017. School going studying in $8^{\text {th }}$ to $12^{\text {th }}$ standards from both government and private secondary and senior secondary schools in the rural block comprised the study population. The study was undertaken between the period of October 2016 to July 2017.

One of recent meta-analysis carried out on schoolbased studies in the year 2013 on prevalence of child and adolescent psychiatric disorders in India, done by Patra et $\mathrm{al}^{17}$ reported the prevalence to be $23.33 \%$. Taking prevalence to be $23 \%$ and allowable error to be $15 \%$ of prevalence, the sample size was thus calculated to be 595. So, for the purpose of present study 600 subjects were selected.

List of schools were obtained from DEO (District Education Officer). Prior permission from the DEO was obtained for the present study after briefing him about study purpose and objectives. All the senior secondary schools in that block were stratified into two groups i.e. government and private. A total of 3 schools from each stratum were selected randomly by lottery method from list of all eligible schools.

All those schools which had strength of more than 100 students from 8 th to 12 th class and at least 20 students in each of these classes qualified the eligibility criteria were included in the study for the purpose of adequacy of sample size. A total of six schools were selected. A total of 600 students, 100 from each school and 20 from each class were selected taking both boys and girls from each class in equal proportion. Simple random sampling technique using lottery method was used to select students from each class. 
Prior permission was obtained from the concerned principals of the selected schools after briefing them about the study and its objectives. A written informed consent from parents of the selected students was obtained one day prior to conducting the study through principal/class teacher. Verbal assent of students under the age of 18 years and written consent of students aged 18 years \& above and of parents in case of minor students was obtained. Students who did not consent or those who were absent on the day of survey as well as those having gross hearing impairment, diagnosed organic brain pathology or articulation disorders were not considered for the study purpose.

Symptom checklist-90 Revised version was used to assess different symptoms and states of the mind. ${ }^{18}$ It comprises of 90 questions. This scale measures somatization, obsessive-compulsive disease, inter-personal sensibility, depression, anxiety, hostility, phobic anxiety, paranoid thoughts, psychotic and additional symptoms on 5-point Likert scale ( $0=$ none and $4=$ too much). The SCL-90 takes between 12 and 20 minutes to complete.

Raw score of SCL 90 R subscales was calculated by dividing the sum of scores for a dimension by number of items in the dimension. A cut off of each subscale scores $>1$ as suggestive of possible psychopathology was used based on the study of Siri C and his colleagues. ${ }^{19}$ In addition, the whole study group was subdivided into three categories within each subscale to better characterize differences between students with and without psychopathological symptoms i.e. Students without the symptom = scores $<1$; with mild symptoms = scores $1-2$; with moderate - severe symptoms $=$ scores $>2$.

The SCL 90 R has 3 global indexes: Global Severity Index (GSI) that measures the extent or depth of the individual's psychiatric disturbances; Positive Symptom Total (PST) counts the total number of questions rated above 1 point; Positive Symptom Distress Index (PSDI) is calculated by dividing the sum of all items values by the PST. The global severity index (GSI) for SCL-90 R is calculated as the average score of the 90 items of the questionnaire.

Additionally, the socio demographic level of each student was studied to know the association of those factors with anxiety.

Additionally, the modified B G Prasad scale was used to assess socioeconomic status of study population. ${ }^{20}$

The data were analyzed using SPSS V.20.0 (Statistical package for social sciences) software. After analysis of the data, individuals with high cut off value was referred to Psychiatrist for detailed evaluation and for further management.

\section{Results}

Table 1 describes the various socio-demographic details of the study population. There was equal distribution of students between government and private schools in terms of class and gender. Maximum number of students belonged to age group of $13-14$ years (50\%) followed by $15-16$ years $(40.7 \%)$ and $17-18$ years $(9.33 \%)$ in both government and private schools. In government school $40.2 \%$ of students were from lower middle class followed by lower class $(27.6 \%)$ but in private school maximum number of students (28\%) was from middle class followed by upper middle class (25.3\%). In government school only $0.7 \%$ students were from upper class as compared to private schools where $18.7 \%$ students were from upper class. It was observed that fathers of $64.7 \%$ of the students in private school were educated up to $11-12$ class and above followed by $9-10$ class (29.3\%), $1-8$ class ( $5.3 \%)$ and only $0.7 \%$ were illiterate. Whereas in government schools, fathers of $40.7 \%$ of the students were literate till 9-10 class followed by $1-8$ class (32.3\%), $11-12$ class and above $21.7 \%$ and $5.3 \%$ were illiterate. Mothers of $51 \%$ of students in government schools were educated up to 1-8 class followed by $9-10$ class, only $7 \%$ were educated till $11-12$ class and above and $16.7 \%$ were illiterate. Comparatively, in private school, mothers of $46.3 \%$ of students were educated till 9-10 class followed by $11-12$ class and above (36.7\%) and only $2.7 \%$ mothers were illiterate. In government school mothers of $16 \%$ were employed which was slightly less in comparison to private school where $18.3 \%$ student's mother were employed.

Table 1.Distribution of students according to socio demographic profile among students of government and private schools

\begin{tabular}{|c|c|c|c|}
\hline Variables & Government Sr. Sec. Schools (\%) $\mathbf{n = 3 0 0}$ & Private Sr. Sec. School (\%) $\mathbf{n = 3 0 0}$ & Total \\
\hline \multicolumn{3}{|c|}{ Age } \\
\hline $13-14$ years & $143(47.5 \%)$ & $157(52.3 \%)$ & $300(50 \%)$ \\
\hline $15-16$ years & $127(42.2 \%)$ & $117(39 \%)$ & $244(40.7 \%)$ \\
\hline $17-19$ years & $30(10.0 \%)$ & $26(8.7 \%)$ & $56(9.33 \%)$ \\
\hline \multicolumn{3}{|c|}{ Class } \\
\hline $8^{\text {th }}$ class & $60(20 \%)$ & $60(20 \%)$ & $120(20 \%)$ \\
\hline
\end{tabular}




\begin{tabular}{|c|c|c|c|}
\hline $9^{\text {th }}$ class & $60(20 \%)$ & $60(20 \%)$ & $120(20 \%)$ \\
\hline $10^{\text {th }}$ class & $60(20 \%)$ & $60(20 \%)$ & $120(20 \%)$ \\
\hline $11^{\text {th }}$ class & $60(20 \%)$ & $60(20 \%)$ & $120(20 \%)$ \\
\hline 12 class & $60(20 \%)$ & $60(20 \%)$ & $120(20 \%)$ \\
\hline \multicolumn{4}{|c|}{ Gender } \\
\hline Males & $150(50 \%)$ & $150(50 \%)$ & $300(50 \%)$ \\
\hline Females & $150(50 \%)$ & $150(50 \%)$ & $300(50 \%)$ \\
\hline \multicolumn{4}{|c|}{ Socio economic status (According to Modified B.G Prasad scale) } \\
\hline Upper class & $2(0.7 \%)$ & $56(18.7 \%)$ & $58(9.7 \%)$ \\
\hline Upper middle class & $25(8.3 \%)$ & $76(25.3 \%)$ & $101(16.8 \%)$ \\
\hline Middle class & $69(22.9 \%)$ & $84(28.0 \%)$ & $153(25.5 \%)$ \\
\hline Lower middle class & $121(40.2 \%)$ & $64(21.3 \%)$ & $185(30.8 \%)$ \\
\hline Lower class & $83(27.6 \%)$ & $20(6.7 \%)$ & $103(17.2 \%)$ \\
\hline \multicolumn{4}{|c|}{ Literacy level of father } \\
\hline Illiterate & $16(5.3 \%)$ & $2(0.7 \%)$ & $18(3 \%)$ \\
\hline 1-8 class & $97(32.3 \%)$ & $16(5.3 \%)$ & $113(18.8 \%)$ \\
\hline 9-10 class & $122(40.7 \%)$ & $88(29.3 \%)$ & $210(35 \%)$ \\
\hline $\begin{array}{c}\text { 11-12 class and } \\
\text { above }\end{array}$ & $65(21.7 \%)$ & $194(64.7 \%)$ & 259 (43.1\%) \\
\hline \multicolumn{4}{|c|}{ Literacy level of mother } \\
\hline Illiterate & $50(16.7 \%)$ & $8(2.7 \%)$ & $58(9.7 \%)$ \\
\hline $1-8$ class & $153(51.0 \%)$ & $43(14.3 \%)$ & $196(32.7 \%)$ \\
\hline 9-10 class & $76(25.3 \%)$ & $139(46.3 \%)$ & $215(35.8 \%)$ \\
\hline $\begin{array}{c}\text { 11-12 class and } \\
\text { above }\end{array}$ & $21(7.0 \%)$ & $110(36.7 \%)$ & $131(21.8 \%)$ \\
\hline \multicolumn{4}{|c|}{ Mother's employment status } \\
\hline Employed & $48(16.0 \%)$ & $55(18.3 \%)$ & $103(17.1 \%)$ \\
\hline Unemployed & $252(84 \%)$ & 245 (81.7\%) & 497 (82.9\%) \\
\hline
\end{tabular}

Table 2.Distribution of grades of anxiety among study subjects

\begin{tabular}{|c|c|c|}
\hline Subscale & Frequency $(\mathbf{n}=\mathbf{6 0 0})$ & Percentage \\
\hline No Anxiety & 489 & 81.5 \\
\hline Mild Anxiety & 109 & 18.2 \\
\hline Moderate to severe Anxiety & 2 & 0.3 \\
\hline Total & 600 & $100 \%$ \\
\hline
\end{tabular}

Table 3.Distribution of anxiety among study subjects according to type of school

\begin{tabular}{|c|c|c|}
\hline Variable & Government school (\%) $\mathbf{n}=\mathbf{3 0 0}$ & Private school (\%) $\mathbf{n}=\mathbf{3 0 0}$ \\
\hline No anxiety & $241(80.3 \%)$ & $248(82.7 \%)$ \\
\hline Mild anxiety & $58(19.3 \%)$ & $51(17.0 \%)$ \\
\hline Moderate to severe anxiety & $1(0.3 \%)$ & $1(0.3 \%)$ \\
\hline
\end{tabular}


Table 4.Distribution of anxiety on basis of socio demographic profile of the study subjects

\begin{tabular}{|c|c|c|c|}
\hline Variable & Students without anxiety & Students with anxiety & Level of significance \\
\hline \multicolumn{4}{|c|}{ Age } \\
\hline $13-14$ years & $246(82.0 \%)$ & $54(18 \%)$ & \multirow[t]{3}{*}{$x^{2}=5.687, d f=2, p=0.058$} \\
\hline $15-16$ years & $203(83.2 \%)$ & $41(16.8 \%)$ & \\
\hline $17-19$ years & $39(69.6 \%)$ & $17(30.4 \%)$ & \\
\hline \multicolumn{4}{|c|}{ Class } \\
\hline $8^{\text {th }}$ class & $99(82.5 \%)$ & $21(17.5 \%)$ & \multirow[t]{5}{*}{$x^{2}=3.331, d f=4, p=0.504$} \\
\hline $9^{\text {th }}$ class & $100(83.3 \%)$ & $20(16.7 \%)$ & \\
\hline $10^{\text {th }}$ class & $96(80.7 \%)$ & $23(19.3 \%)$ & \\
\hline $11^{\text {th }}$ class & $101(84.2 \%)$ & $19(15.8 \%)$ & \\
\hline 12 class & $92(76 \%)$ & $29(24 \%)$ & \\
\hline \multicolumn{4}{|l|}{ Gender } \\
\hline Males & $259(86.3 \%)$ & $41(13.7 \%)$ & \multirow[t]{2}{*}{$x^{2}=9.880, d f=1, p=0.002$} \\
\hline Females & $229(76.3 \%)$ & $71(23.7 \%)$ & \\
\hline \multicolumn{4}{|c|}{ Socio economic status (According to Modified B.G Prasad scale) } \\
\hline Upper class & $44(75.9 \%)$ & $14(24.1 \%)$ & \multirow[t]{5}{*}{$x^{2}=3.043, d f=4, p=0.551$} \\
\hline Upper middle class & $85(84.2 \%)$ & $16(15.8 \%)$ & \\
\hline Middle class & $125(81.7 \%)$ & $28(18.3 \%)$ & \\
\hline Lower middle class & $154(83.2 \%)$ & $31(16.8 \%)$ & \\
\hline Lower class & $80(77.7 \%)$ & $23(22.3 \%)$ & \\
\hline \multicolumn{4}{|c|}{ Literacy level of father } \\
\hline Illiterate & $15(83.3 \%)$ & $3(16.7 \%)$ & \multirow[t]{4}{*}{$x^{2}=0.681, d f=3, p=0.878$} \\
\hline $1-8$ class & $89(78.8 \%)$ & $24(21.2 \%)$ & \\
\hline $9-10$ class & $171(81.4 \%)$ & $39(18.6 \%)$ & \\
\hline 11-12 class and above & $213(82.2 \%)$ & $46(17.8 \%)$ & \\
\hline \multicolumn{4}{|c|}{ Literacy level of mother } \\
\hline Illiterate & $46(79.3 \%)$ & $12(20.7 \%)$ & \multirow[t]{4}{*}{$x^{2}=6.940, d f=3, p=0.074$} \\
\hline $1-8$ class & $171(87.2 \%)$ & $25(12.8 \%)$ & \\
\hline 9-10 class & $170(79.1 \%)$ & 45 (20.9\%) & \\
\hline 11-12 class and above & $101(77.1 \%)$ & $30(22.9 \%)$ & \\
\hline \multicolumn{4}{|c|}{ Mother's employment status } \\
\hline Unemployed & $400(80.5 \%)$ & 97 (19.5\%) & \multirow[t]{2}{*}{$x^{2}=1.379, \mathrm{df}=1, \mathrm{p}=0.240$} \\
\hline Employed & $88(85.4 \%)$ & $15(14.6 \%)$ & \\
\hline
\end{tabular}

In table 2 , shows that, nearly $18.5 \%$ adolescents suffered from anxiety out of which $18.2 \%$ suffered from mild anxiety and $0.3 \%$ suffered from moderate to severe anxiety.

As depicted in table 3, in government school $19.3 \%$ students had mild anxiety and $0.3 \%$ had moderate to severe anxiety whereas in private school students $17 \%$ had mild anxiety and $0.3 \%$ had moderate to severe anxiety. This difference was found statistically non-significant $(p=>0.05)$.

In table 4, it was found that anxiety was highest in late adolescent phase (30.4\%) followed by $13-14$ years (18\%) and minimum in age group of $15-16$ years $(16.8 \%)$ but this variation was statistically non- significant. Anxiety was maximum in $10^{\text {th }}$ and $12^{\text {th }}$ standard students which were $19.3 \%$ and $24 \%$ respectively but this difference was statistically non- significant. Anxiety was significantly high among females (23.7\%) than males (13.7\%). Anxiety was maximum in upper and lower socio-economic class of students with $24.1 \%$ and $22.3 \%$ respectively but this was statistically non-significant. Anxiety was more among students whose mothers were unemployed (19.5\%) than 
those whose mothers were employed (14.6\%) but this association was non-significant. Distribution of anxiety with literacy level of father and mother was found statistically non-significant.

\section{Discussion}

In the present study, the overall prevalence of anxiety was $18.5 \%$ with mild anxiety to be $18.2 \%$ and moderate to severe anxiety to be $0.3 \%$. The results are in line with the finding of a study done among German adolescents by Essau $\mathrm{C}$ et al., where they found prevalence of anxiety to be $18.6 \% .^{7}$ Last CG et al. in his study concluded that anxiety disorder was $16 \%$ among children. ${ }^{16}$ In the study conducted by Deb S et al., anxiety was prevalent in $20.1 \%$ of boys and $17.9 \%$ of girls. ${ }^{21}$ Beesdo $\mathrm{K}$ et al. in his study stated that the lifetime prevalence of any anxiety disorder in children or adolescents is about $15 \%$ to $20 \% .^{22}$

In the present study, it was observed that government school students (19.3\%) have more anxiety than private school students (17\%) but this association was non-significant. The study conducted by Bihari S et al. found out that mean score of anxiety among government school adolescents was significantly higher than private school students. ${ }^{28}$ Anxiety is more in government school adolescents as in India, the facilities for better education is less available in government schools and in present competitive scenario, they may lag behind. So they are at more stress and thus suffer more from anxiety.

In the present study, the distribution of anxiety was significantly more among females ( $n=71,23.7 \%$ ) as compared to males $(n=41,13.7 \%$ ) with $p$ value of 0.002 $(<0.05)$. The finding was similar to the study done by Michalčáková $\mathrm{R}$ et al., where girls reported a higher number and intensity of fears and anxiety compared to boys. ${ }^{23}$ According to King $\mathrm{NJ}$ et al. females reported more fear and anxiety than males. ${ }^{24}$ Essau $\mathrm{C}$ et al. in his study done on German adolescents found that anxiety was more among adolescent girls than adolescent boys. ${ }^{7}$ In Indian scenario there is gender inequality in most of the families; boys were given comparatively more freedom, independence and opportunities to come out with their inherent qualities in comparison to girls. So, girls were unable to express freely about their feelings and problems and thus were at more stress. They were supposed to stay at home after their school hours and managed household responsibilities along with their studies. They were also less supported emotionally by other members of family like grandparents and thus felt lonelier and stressed. That was why girls were comparatively more prone to develop anxiety.

The association of anxiety with regards to gender was different from our study where prevalence was more in males than females as revealed by some other studies. Deb $\mathrm{S}$ et al. reported in his study that males were having more anxiety than females. ${ }^{21}$ According to Rao JVRC, mean anxiety score in case of adolescent boys was slightly higher than in adolescent girls. ${ }^{25}$ It may be because boys continue to face more pressure regarding their proper choice of vocation and future career.

In the present study, anxiety was maximum in $12^{\text {th }}$ class student $(24 \%)$ followed by $10^{\text {th }}$ class student $(19.3 \%)$. It was almost equally distributed among $8^{\text {th }}, 9^{\text {th }}$ and $11^{\text {th }}$ class students but this association was found to be non-significant. The finding is similar to study conducted by Bhasin SK et al., where mean rank of anxiety was significantly higher among board classes students i.e. $10^{\text {th }}$ and $12^{\text {th }}$ class as compared to $9^{\text {th }}$ and $11^{\text {th }}$ class. ${ }^{26} 10^{\text {th }}$ and $12^{\text {th }}$ class students are having more anxiety as parents put pressure on their children for better performance because of their concern for the welfare of their children and their awareness of the competition for getting admission in reputed institutions.

In the present study, late adolescents (17-19 years - $30.4 \%)$, were having more anxiety in comparison to mid adolescents (15-16 years- $16.8 \%$ and $13-14$ years $-18 \%$ ). The finding was in accordance with study done by Nair MKC et al., where higher the age of the adolescent, more was the severity of phobia and anxiety among them ${ }^{27}$ Beesdo K et al. in his study also found that prevalence estimates tend to further increase with age among children and adolescents. ${ }^{22}$ As in our culture, an individual's intellectual abilities are judged and status is ascribed on the basis of academic performance, thus students become more anxious over their academic success and failures as they age.

In the present study, anxiety was more among students who belonged to upper class (24.1\%) and lower class (22.3\%) but the distribution of anxiety according to socio economic status was found to be significantly non-significant. Deb S et al. in his study found that anxiety was highest in middle SES group followed by lower SES group and then higher SES group. ${ }^{21}$

Groups belonging to lower class are having more anxiety due to their insecurity about their future, stress of getting better education due to economic constrain, responsibility of earning bread apart from their academic performance. Adolescents belonging to upper class are economically and socially more developed. Parents are having more desires and expectations from their child in order to hold their social position, thus leading to anxiety among their children.

In the present study anxiety was more among adolescents whose mothers were non-working (19.5\%) as compared to adolescents whose mothers were employed. Children of employed mothers often experience less anxiety as adolescents appear to be socially mature since employed mothers are more inclined than unemployed mothers to grant their children independence and autonomy when their youngsters are ready for it. When mothers have 
stimulating jobs, they receive adequate social support from their husbands and other close associates, and are highly committed to being a parent, they have generally favorable impressions of their children, rely less on power assertion to control their behavior, and are inclined to take an authoritative approach to child rearing - precisely the parenting style so often associated with favorable cognitive, social and emotional outcomes.

This finding of present study was different to the finding of Deb S et al., where mean anxiety score of adolescents whose mothers were working was higher than non-working mothers. ${ }^{21}$ According to Bhasin SK et al., level of anxiety was higher among students with working mothers than students whose mothers were housewives. ${ }^{26}$

In the present study, anxiety was not affected by mother's literacy level. According to Bhasin SK et al. also no significant association of anxiety was observed with mother's literacy level. ${ }^{26}$

\section{Conclusion}

The study concludes that about one-fifth of the adolescents suffers from anxiety. Females tend to suffer more of anxiety than males. Adolescents of $10^{\text {th }}$ and $12^{\text {th }}$ class who have to appear in their board exams suffer more anxiety than other adolescents. Late adolescence students suffer more of anxiety than mid adolescence students. Adolescents who belong to upper and lower class are at higher risk of anxiety than other socio-economic class of students. Adolescents whose mothers are unemployed are at greater risk of anxiety than students whose mothers are employed.

\section{Recommendations}

The relationship between an adolescent's academic success and anxiety is curvilinear - a minimal amount of anxiety tends to enhance academic performance, but excessive anxiety undermines academic performance.

As it is evident that cognitive-behavioral treatment and skills can reduce levels of anxiety among adolescents, they should be taught how to manage stress and anxiety at schools.

Parent education is specifically required to deal with educational pressure and to avoid comparison of the performance of one's own child with the best ranked students.

\section{Conflict of Interest: None}

\section{References}

1. Costello EJ, Mustillo S, Erkanli A et al. Prevalence and development of psychiatric disorders in childhood and adolescence. Arch Gen Psychiatry 2003; 60: 837-44.
2. Bernstein GA, Borchardt CM. Anxiety disorders of childhood and adolescence: A critical review. Journal of the American Academy of Child and Adolescent Psychiatry 1991; 30: 519-32.

3. Boyd CP, Kostanski M, Gullone E et al. Prevalence of anxiety and depression in Australian adolescents: Comparisons with worldwide data. The Journal of Genetic Psychology 2000; 161: 479-92.

4. Student Mental Health Working Group. CR166. The mental health of students in higher education. Royal College of Psychiatrists, London.; 2011: 97.

5. World Health Organization. The world health report 2001 - mental health: new understanding, new hope. The World Health Organization, Geneva. 2001.

6. Deb S. A study on the negative effects of academic stress. The International Seminar on Learning and Motivation, Kedah Darul Aman, Malaysia. 2001.

7. Essau, CA, Conradt J, Petermann F. Frequency, comorbidity and psychosocial impairment of anxiety disorders in German adolescents. Journal of Anxiety Disorders 2000; 14: 263-79.

8. Albano AM, Chorpita BF, Barlow DH. Childhood anxiety disorders. In: Mash EJ, Barkley RA (Eds.), Child Psychopathology. Guilford Press, New York. 2003: 279-329.

9. Bokhorst K, Goossens FA, De Ruyter PA. Early detection of social anxiety: reliability and validity of a teacher questionnaire for the identification of social anxiety in young children. Social Behavior and Personality 2001; 29: 787-98.

10. Donovan CL, Spence SH. Prevention of childhood anxiety disorders. Clinical Psychology Review 2000; 20(4): 509-31.

11. McLoone J, Hudson JL, Rapee R. Treating anxiety disorders in a school setting. Education and Treatment of Children 2006; 29 (2): 219-42.

12. Guarnaccia PJ. A cross-cultural perspective on anxiety disorders. In: Friedman S (Ed.), Cultural issues in the treatment of anxiety. Guilford, New York. 1997: 3-20.

13. Essau CA. Comorbidity of anxiety disorders in adolescents. Depress Anxiety 2003; 18(1): 1-6.

14. Cummings CM, Caporino NE, Kendall PC. Comorbidity of anxiety and depression in children and adolescents: 20 years after. Psychol Bull 2014; 140(3): 816-45.

15. Woodward LJ, Fergusson DM. Life course outcomes of young people with anxiety disorders in adolescence. The American Academy of Child and Adolescent Psychiatry 2001; 40(9): 1086-93.

16. Last CG, Perrin S, Hersen M, et al. A prospective study of childhood anxiety disorders. J Am Acad Child Adolesc Psychiatry 1996; 35(11): 1502-10.

17. Malhotra S, Patra BN. Prevalence of child and adolescent psychiatric disorders in India: a systematic review and meta-analysis. Child and Adolescent Psychiatry and Mental Health 2014; 8: 22.

18. Derogatis LR, Lipman RS. The SCL 90: An outpatient 
psychiatric rating scale. Psychopharmacol Bull 1973; 9: 13-28.

19. Siri C, Cilia R, Gaspari DD et al. Psychiatric symptoms in Parkinson's disease assessed with the SCL-90R selfreported questionnaire. Neurol Sci 2009; 31: 35-40.

20. Khairnar M, Wadgave U, Shimpi PV. Updated BG Prasad socioeconomic classification for 2016. J Indian Assoc Public Health Dent 2016; 14: 469-70.

21. Deb S, Chatterjee P, Walsh K. Anxiety amongst high school students in India. Australian Journal of Educational \& Developmental Psychology 2010; 10: 18-31.

22. Beesdo K, Knappe S, Psycha D, et al. Anxiety and anxiety disorders in children and adolescents: developmental issues and implications for DSM-V. Psychiatr Clin North Am 2009; 32(3): 483-524.

23. Michalčáková R, Lacinová L. Fears in Adolescence. Psihologijske teme 2009; 18(1): 21-36.

24. King NJ, Ollier K, lacuone R et al. Fears of children and adolescents: a cross-sectional Australian study using the revised-fear survey schedule for children. Journal of Child Psychology and Psychiatry 1989; 30: 775-84.

25. Rao JVRC. Anxiety among adolescent students. Conflux Journal of Education 2014; 2(4): 25-8.

26. Bhasin SK, Sharma R, Saini NK. Depression, anxiety and stress among adolescent students belonging to affluent families: a school-based study. Indian Journal of Pediatrics 2010; 77: 161-5.

27. Nair MKC, Russell PSS, Subramaniam VS et al. Dad 8: school phobia and anxiety disorders among adolescents in a rural community population in India. Indian J Pediatr 2013; 80(2): 171-4.

28. Bihari S. Academic Anxiety among secondary school students with reference to gender, habitat and types of school. International Journal of Education and Psychological Research 2014; 3(4): 30-2.

Date of Submission: 2018-10-03 Date of Acceptance: 2018-10-30 